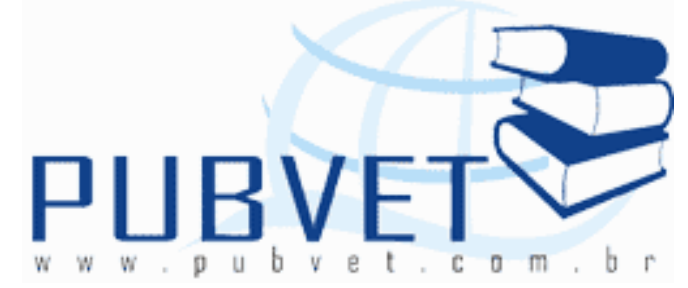

PUBVET, Publicações em Medicina Veterinária e Zootecnia.

\title{
Leucose enzoótica bovina - revisão
}

\section{Diego Lobon Jimenez Filho ${ }^{1}$ e Cláudia Ribeiro do Valle ${ }^{2}$}

1 Médico Veterinário, Mestre em Zootecnia pela Universidade de São Paulo, Pirassununga-SP, Brasil. diegojimenez@usp.br

2 Médica Veterinária, Professora em Medicina Veterinária - Pontifícia Universidade Católica de Minas Gerais (PUC-MG/Poços de Caldas)

\section{Resumo}

A leucose enzoótica bovina (LEB) é uma enfermidade infecto-contagiosa causada pelo vírus da leucose bovina (VLB). Praticamente se encontra disseminada nos rebanhos do mundo todo. O vírus provoca linfocitose persistente que pode progredir para a doença neoplásica, denominada linfoma. A LEB causa prejuízos econômicos, por reduzir a produtividade animal e causar imunossupressão, predispondo às infecções secundárias e morte do animal. Devido à inexistência de tratamento ou de uma vacina eficaz, medidas de prevenção e controle se fazem extremamente necessárias para o controle e erradicação da LEB. O objetivo desta revisão de literatura é trazer informações sobre a importância da doença, etiologia, epidemiologia, patogenia, sinais clínicos, diagnóstico e controle.

Palavras-chave: Bovinos. Vírus da Leucose Bovina. Leucose Enzoótica Bovina. 
JIMENEZ FILHO, D.L. e VALLE, C.R. Leucose enzoótica bovina - revisão. PUBVET, Londrina, V. 7, N. 21, Ed. 244, Art. 1611, Novembro, 2013.

\title{
Enzootic bovine leukosis - review
}

\begin{abstract}
The enzootic bovine leukemia (LEB) is an infectious disease caused by bovine leukemia virus (BLV). Practically it is widespread in flocks across the world. The virus causes persistent lymphocytosis which may progress to neoplastic disease called lymphoma. LEB cause economic losses by reducing animal productivity, and cause immunosuppression predisposes to secondary infections and death of the animal. Due to lack of treatment or an effective vaccine, prevention and control is extremely necessary to make the control and eradication of the LEB. The aim of this review is to bring information about the importance of disease, etiology, epidemiology, pathogenesis, clinical signs, diagnosis and control.
\end{abstract}

Keywords: Bovine Leukosis Virus, Bovine Leukosis, Cattle.

\section{Introdução}

Leucose enzoótica bovina (LEB), também conhecida como linfoma bovino ou leucemia bovina, é uma enfermidade infecto-contagiosa de origem viral, de notificação obrigatória, conforme a Oficina Internacional de Epizootias (OIE, 2012) e que se caracteriza por uma neoplasia maligna do tecido linfóide dos bovinos (BRAGA, 1998; MALATESTINIC, 2003). Atualmente está disseminada nos rebanhos bovinos do mundo todo, com ampla variação na prevalência, (OTT et al. 2003).

A doença tem longo período de evolução e frequentemente, apresenta-se de forma inaparente, sendo o animal assintomático um importante transmissor do vírus (BARROS FILHO et al. 2009). A infecção pelo Vírus da Leucose Bovina (VLB) tem sido associada diretamente com redução dos níveis de produtividade de leite, alta taxa de abate e descarte voluntário prematuro, perdas por mortalidade e aborto, e perdas reprodutivas (ACAITE et al. 2007). 
JIMENEZ FILHO, D.L. e VALLE, C.R. Leucose enzoótica bovina - revisão. PUBVET, Londrina, V. 7, N. 21, Ed. 244, Art. 1611, Novembro, 2013.

\section{Desenvolvimento}

\section{Etiologia}

O Vírus da Leucemia Bovina é o agente etiológico da Leucose Enzoótica Bovina (FLORES, 2007), sendo classificado como oncovírus tipo C exógeno da família Retroviridae (RADOSTITS et al. 2002). A partícula viral mede de 90$120 \mathrm{~nm}$ (nanômetros) de diâmetro e é constituída por um capsídeo icosaédrico e envelope lipoglicoprotéico (LEUZZI JUNIOR et al. 2001). Os vírus infectam principalmente linfócitos $B$, porem linfócitos $T$ também pode ser infectado, além de monócitos e granulócitos (SILVA et al. 2008).

$O$ vírus da LEB é muito lábil frente às influências exteriores. As radiações ultravioletas, o congelamento e descongelamento repetidos, assim como o aquecimento a $56^{\circ} \mathrm{C}$ durante 30 minutos inativam o vírus (BEER, 1999). Pasteurização, também inativa os vírus, porem, estes podem permanecer viáveis por até 2 semanas em sangue armazenado à $4^{\circ} \mathrm{C}$ (ANDREWS et al. 2004). Solventes e detergentes lipídicos, tais como o álcool, éter e clorofórmio, também inativam os retrovírus (BRAGA et al. 1998).

\section{Epidemiologia}

\section{Prevalência}

Atualmente, a LEB é distribuída mundialmente, porém com grandes variações regionais (ANDREWS et al. 2004). No Brasil o primeiro relato da doença foi feito por (RANGEL \& MACHADO, 1943), sendo registrada em praticamente todos os estados (MENDES et al. 2008), a prevalência da enfermidade no país é de 27,6\% (BARROS FILHO et al. 2009).

A região sudeste tem maior expressividade, com média de 39,8\% de animais positivos (MENDES et al. 2008). Em Goiás, em 18 municípios da bacia leiteira, os resultados encontrados foram de $46 \%$ de animais reagentes para raça Holandesa, 36,5\% para mestiços Holandês/Zebu, 25\% para Gir e 13,2\% para Nelore (SPONCHIADO, 2008). No Nordeste, a ocorrência da LEB se apresenta entre $5,1 \%$ a $16,9 \%$ (MENDES et al. 2008). 
JIMENEZ FILHO, D.L. e VALLE, C.R. Leucose enzoótica bovina - revisão. PUBVET, Londrina, V. 7, N. 21, Ed. 244, Art. 1611, Novembro, 2013.

\section{Transmissão}

Assim como os outros retrovírus, o VLB apresenta baixa transmissibilidade, ocorrendo predominantemente entre animais do mesmo rebanho, sendo incomum ocorrer entre rebanhos vizinhos (FLORES, 2007). A transmissão do VLB ocorre essencialmente via horizontal pela exposição a fluidos biológicos contaminados com linfócitos infectados, principalmente sangue (SANTOS et al. 2007; SILVA et al. 2008).

A principal via de transmissão é a iatrogênica, através de procedimentos que permitam a transferência de sangue contaminado entre os animais, (FLORES, 2007; SANTOS et al. 2007), como por exemplo, o tatuador, descornador, seringas hipodérmicas, materiais cirúrgico, aplicação de vacinas, administração de medicamentos, (MALATESTINIC, 2003; FLORES, 2007), coleta de sangue de vários animais com agulha comum e transfusões sanguíneas (SILVA et al. 2008). Quantidades de sangue tão pequenas quanto 0,1 $\mu$ lão capazes de transmitir o vírus (ANDREWS et al. 2004; FLORES, 2007). A infecção também pode ser transmitida via teste intradérmico de tuberculina (RADOSTITS et al. 2002; ANDREWS et al. 2004).

O uso de luvas contaminadas com sangue da palpação retal de animais soropositivos, para palpar animais soronegativos, resulta na transmissão de infecção, como evidenciado pela formação de anticorpo, o que representa a possibilidade de que o vírus seja transmitido por exame retal dos bovinos (LEUZZI JUNIOR et al. 2001; SILVA et al. 2008).

A transmissão pela monta natural pode ocorrer, sendo uma forma de disseminação do vírus de touros infectados para fêmeas, devido à possível presença de linfócitos no trato reprodutivo, e não à presença do VLB nos espermatozóides (FLORES, 2007).

A presença do vírus já foi descrita em secreções traqueais, bronquiais, nasais, na saliva (ANDREWS et al. 2004) e também na glândula mamária, associada aos linfócitos, bem como no leite, indicando a possibilidade de transmissão através do leite e colostro (ANDREWS et al. 2004; ACAITE et al. 2007; FLORES, 2007). 
JIMENEZ FILHO, D.L. e VALLE, C.R. Leucose enzoótica bovina - revisão. PUBVET, Londrina, V. 7, N. 21, Ed. 244, Art. 1611, Novembro, 2013.

Em algumas regiões, a alta densidade de insetos hematófagos é importante, pois os tabanídeos participam ativamente na disseminação do VLB (SANTOS et al. 2007; SILVA et al. 2008). Já a mosca-dos-estábulos (Stomoxys calcitrans), não é descrita como vetor para a LEB, pois, possui pequeno volume bucal, carreando quantidades insuficientes de linfócitos sanguíneos para transmitir o vírus (RADOSTITS et al. 2002).

\section{Patogenia}

Bovinos infectados são portadores permanentes do VLB (MALATESTINIC, 2003). A LEB caracteriza-se por um curto período de viremia pós-infecção, seguido por um longo período de latência (1 a 8 anos) antes do aparecimento de sinais clínicos (KURTINAITIENE et al. 2008). Após um intervalo de 10 a 12 dias, partículas virais estão presentes na corrente sanguínea induzindo uma resposta imune humoral com a produção de anticorpos específicos (LEUZZI JUNIOR et al. 2001).

O VLB compromete principalmente o sistema linfóide dos bovinos infectados, onde inicia processos patológicos nos tecidos e órgãos, especialmente linfonodos, promovendo, por leucemização, a formação progressiva de linfomas (FERNANDES et al. 2009). Braga et al. (1998), também salientam que há possibilidade do vírus atuar como agente imunossupressor, podendo assim agir como fator predisponente a outras doenças.

\section{Sinais Clínicos}

A infeç̧ão pode permanecer clinicamente silenciosa na forma aleucêmica (presença de anticorpos), porém, cerca de um terço dos infectados, desenvolvem linfocitose persistente e 1-10\% desenvolvem a doença clínica, caracterizada por tumores linfóides (linfomas) (SANTOS et al. 2007).

Os linfomas são encontrados com maior frequência em animais entre quatro e oito anos de idade, onde a doença geralmente causa morte súbita semanas ou meses após o inicio dos sinais clínicos (BARROS FILHO et al. 
JIMENEZ FILHO, D.L. e VALLE, C.R. Leucose enzoótica bovina - revisão. PUBVET, Londrina, V. 7, N. 21, Ed. 244, Art. 1611, Novembro, 2013.

2009). É comum o aumento de linfonodos superficiais principalmente os préescapulares (FIG. 1 e 2), mamários, mandibulares e viscerais (FIG. 3) (LUDERS, 2001).

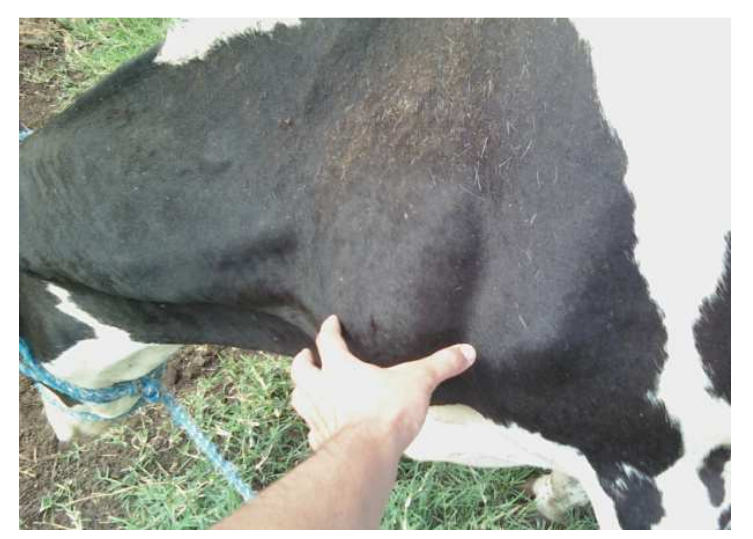

FIG 1: Hiperplasia de linfonodo pré-escapular

Fonte: Arquivo Pessoal

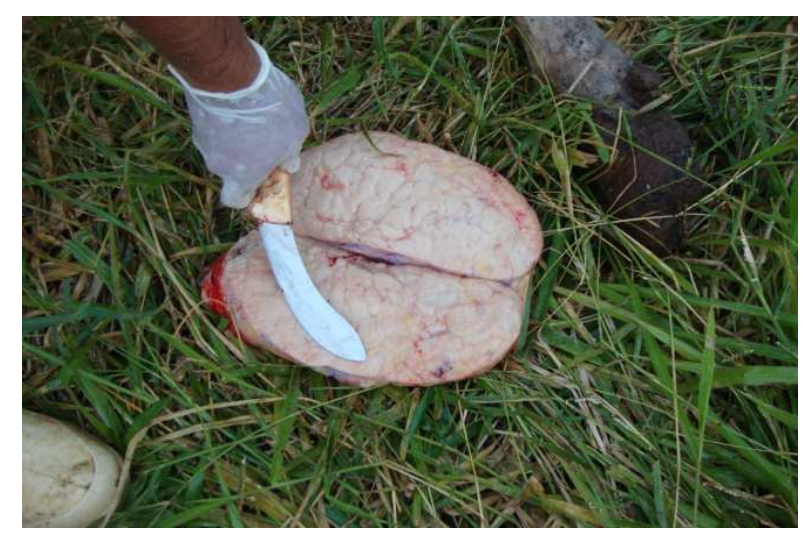

FIG 2: Linfonodo pré-escapular com hiperplasia Fonte: Arquivo Pessoal 


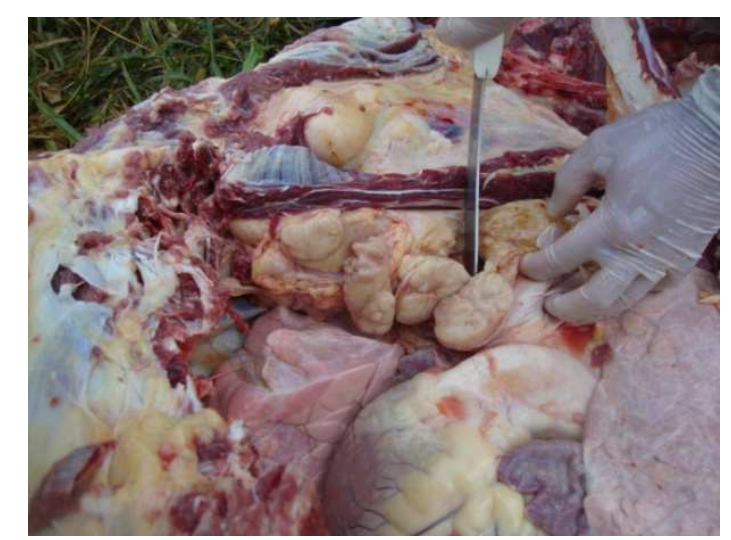

FIG 3: Hiperplasia em linfonodos viscerais Fonte: Arquivo Pessoal

Frequentemente, há invasão do sistema digestório, sendo comum no abomaso, causando obstrução ou úlcera que podem manifestar-se clinicamente como anorexia, timpanismo recorrente, perda de peso e diarréia. Neoplasias localizadas na medula espinhal originam perturbações neurológicas como paralisia de membros posteriores. Casos de falência cardíaca em bovinos são frequentemente associados a linfomas no miocárdio. Os linfomas podem ainda ser encontrados no útero, rins e olhos, neste último caso, causando exoftalmia. Em países cujos sistemas criatórios mantêm registros detalhados de produtividade, como os EUA, Canadá, Japão e Austrália, estima-se que os efeitos do VLB podem atingir uma redução de até $10 \%$ na produção leiteira (FLORES, 2007).

Os achados de necropsia incluem aumentos generalizados dos linfonodos, tanto superficiais como internos. Ao corte, os linfonodos apresentam uma superfície branco-amarelada, sem distinção entre a cortical e medular. Histologicamente observa-se proliferação das células da linhagem linfocítica e infiltração maciça dessas células nos órgãos afetados (FLORES, 2007). 
JIMENEZ FILHO, D.L. e VALLE, C.R. Leucose enzoótica bovina - revisão. PUBVET, Londrina, V. 7, N. 21, Ed. 244, Art. 1611, Novembro, 2013.

\section{Diagnóstico}

Duas condições distintas devem ser consideradas no diagnóstico do VLB: o diagnóstico da infecção (vírus) e o diagnóstico da enfermidade (leucose) (FLORES, 2007).

A infecção pode ser diagnosticada por testes sorológicos e a suspeita da doença clínica, pela observação dos sinais clínicos mencionados anteriormente, a qual deve ser confirmada por exames histopatológicos ou sorológicos. No animal morto, os achados patológicos macro e microscópicos podem confirmar o diagnóstico (FLORES, 2007).

O diagnóstico laboratorial inclui a biópsia de linfonodos suspeitos, os quais são classificados como linfoma. A contagem de linfócitos no exame de sangue pode revelar linfocitose persistente, sugerindo a infecção pelo VLB, entretanto, a ausência de linfocitose persistente não exclui a possibilidade de infecção (BRAGA et al. 1998). Os animais infectados desenvolvem anticorpos, que são regularmente detectados em testes sorológicos como, Imunodifusão em Ágar Gel (IDAG) e Ensaio Imunoenzimático (ELISA), sendo estes os mais utilizados. Radioimunoensaio (RIA), Western Blotting (WB) e Reação em Cadeia da Polimerase (PCR) também podem diagnosticar a LEB (BRAGA et al. 1998).

Reações falso-positivas podem ocorrer em neonatos que receberam anticorpos pelo colostro de mães positivas até os 6 meses de idade. Animais com idade acima de seis meses com resultados positivos por três exames consecutivos (em intervalos de um mês) devem ser considerados como positivos infectados (AGOTTANI et al. 2012).

Já reações falso-negativas podem ocorrer em animais infectados cujo sistema imune ainda não respondeu a infecção viral (janela imunológica). Vacas podem apresentar-se falso-negativas quando os exames sorológicos forem realizados entre duas e seis semanas antes e depois do parto (AGOTTANI et al. 2012). 
JIMENEZ FILHO, D.L. e VALLE, C.R. Leucose enzoótica bovina - revisão. PUBVET, Londrina, V. 7, N. 21, Ed. 244, Art. 1611, Novembro, 2013.

\section{Controle e Prevenção}

Não existe vacina efetiva nem tratamento para os animais. Em consequência disso, medidas para prevenir, controlar ou erradicar a doença se fazem necessárias. (SILVA et al. 2008).

A etapa inicial do programa de controle envolve a realização de testes sorológicos e a identificação dos animais soropositivos. Os animais positivos com idade maior que seis meses, devem ser preferencialmente descartados, mas podem ser mantidos no rebanho desde que separados dos demais e submetidos a práticas que minimizem o risco de transmissão. Bezerros nascidos de mães positivas devem ser alimentados com, colostro e leite pasteurizados ou de vacas livres do VLB e devem ser isolados e retestados aos nove meses, só podendo ser introduzidos no rebanho negativo se mantiver a condição soronegativa. Inicialmente testes sorológicos devem ser realizados a cada 6 meses, a fim de, monitorar a eficácia das medidas adotadas (FLORES, 2007).

Segundo Braga et al. (1998); Andrews et al. (2004); Sponchiado (2008) é de extrema importância, adotar como medidas de controle em rebanhos que possuem animais positivos:

- Utilização de agulhas estéreis individuais para procedimentos profiláticos, clínicos e terapêuticos (aplicação de vacinas, antiparasitários, outros medicamentos, anestésicos e coleta de sangue);

- Utilização de luvas de palpação individuais para cada animal;

- Lavagem e desinfecção de instrumentos cirúrgicos ou de procedimentos potencialmente contaminados com sangue de animal infectado;

- Adoção de programa de controle de insetos hematófagos;

- Uso de inseminação artificial ou utilizar touros soronegativos;

- Separação dos animais em grupos de positivos e negativos a uma distância mínima de 150 metros;

- Ordenhar os lotes de animais negativos primeiro. 
JIMENEZ FILHO, D.L. e VALLE, C.R. Leucose enzoótica bovina - revisão. PUBVET, Londrina, V. 7, N. 21, Ed. 244, Art. 1611, Novembro, 2013.

As propriedades livres do vírus devem adotar medidas para evitar a sua introdução. Para isso, todos os animais adquiridos devem ser testados para o VLB. Se oriundos de rebanhos sabidamente negativos, podem ser incorporados ao rebanho e se oriundos de propriedades de situação desconhecida, devem ser mantidos separados por oito semanas e então, submetidos a um novo teste sorológico (LEUZZI JUNIOR et al. 2001).

\section{Considerações Finais}

A Leucose Enzoótica Bovina está disseminada mundialmente, inclusive no Brasil. O desconhecimento da enfermidade e o fato de que a infecção pode permanecer inaparente em muitos casos, fazem com que a grande maioria dos produtores não manifeste interesse em diagnosticar e erradicar a doença. Porém em rebanhos com alta prevalência, a doença pode causar grandes prejuízos na produção, além de acarretar em doenças secundárias. Por apresentar baixa transmissibilidade, falhas no manejo são as grandes responsáveis pela ampla variação na prevalência desta doença, por isso, é imprescindível que medidas preventivas e sanitárias sejam adotadas, para que ocorra um gradativo saneamento do rebanho, visto que nem sempre é possível descartar todos os animais soropositivos de uma propriedade.

\section{Referências Bibliográficas}

ACAITE, J.; TAMOSIUNAS, V.; LUKAUSKAS, K.; MILIUS, J.; PIESKUS, J. The eradication experience of enzootic bovine leukosis from Lithuania. Preventive Veterinary Medicine, v.82, p.83-89, 2007.

AGOTTANI, J.V.B.; OLIVEIRA, K.B.; FAYSANO, L.; WARTH, J.F.G. Leucose enzoótica bovina: diagnóstico, prevenção e controle. s.d. Disponível em: <http://www.veterinariapreventiva.com.br/leucose.htm> Acesso em: 20 jun. 2012.

ANDREWS, A.H.; BLOWEY, R.W.; BOYD.H.; EDDY, R.G. Bovine Medicine: Diseases and Husbandry of Cattle. 2.ed. Oxford: Blackwell Science, 2004. Chapter 43, p.693-700.

BARROS FILHO, I.R; GUIMARÃES, A.K.; BIONDO, A.W.; KRUGER, E.R.; WAMMES, E.V.; OLLHOFF, R.D.; PIEKARZ, C.H.; SPONCHIADO, D. Prevalência da leucose enzoótica em bovinos leiteiros criados na região metropolitana de Curitiba - Paraná. Ciência Animal Brasileira, suplemento 1, p.513-518, 2009. 
BEER, J. Doenças Infecciosas em Animais Domésticos. São Paulo: Roca, 1999. p.186193.

BRAGA, F.M.; LAAN, C.W.V.D.; SCHUCH, L.F.; HALFEN, D.C. Infecção pelo vírus da leucose enzoótica bovina (BLV). Ciência Rural, v.28, n.1, 1998.

FERNANDES, C.H.C.; MELO, L.E.H.; TENÓRIO, T.G.S.; MENDES, E.I.; FERNANDES, A.C.C.; RAMALHO, T.R.R.; MOURA SOBRINHO, P.A.; MOTA, R.A. Soroprevalência e fatores de risco da infecção pelo vírus da leucose dos bovinos em rebanhos leiteiros da região Norte do estado do Tocantins, Brasil. Arquivo do Instituto Biológico de São Paulo, v.76, n.3, p.327-334, 2009.

FLORES, E.F. VIROLOGIA VETERINÁRIA. Santa Maria: UFSM, 2007. Cap.31, p.811-823.

KURTINAITIENE, B.; AMBROZAITE, D.; LAURINAVICIUS, V.; RAMANAVICIENE, A.; RAMANAVICIUS, A. Amperometric immunosensor for diagnosis of BLV infection. Biosensors and Bioelectronics, v.23, p.1547-1554, 2008.

LEUZZI JUNIOR, L.A.J.; ALFIERI, A.F.; ALFIERI, A.A. Leucose enzoótica bovina e vírus da leucemia bovina. Semina: Ciências Agrárias, v.22, n.2, p.211-221, 2001.

LUDERS, M.A. Prevalência de anticorpo contra o vírus da leucose enzoótica bovina em fêmeas com mais de dois anos no rebanho de bovinos leiteiros no município de Mafra-SC. 2001. 31p. Monografia - Universidade do Estado de Santa Catarina - UDESC, Lages.

MALATESTINIC, A. Bilateral exophthalmos in a Holstein cow with lymphosarcoma. The Canadian Veterinary Journal La Revue vétérinaire canadienne, v.44, p.664-666, 2003.

MENDES, E.I.; FERNANDES, A.C.C.; SÁ, L.M.; SILVA, T.I.B.; BARROS, A.D.; OLIVEIRA, C.M.M.; ALBUQUERQUE, M.S.; SILVA, G.M.S.; SILVA, F.F.; MELO, L.E.H. Prevalência da leucose enzoótica e da tuberculose dos bovinos em rebanhos leiteiros do estado de Pernambuco. In: CONGRESSO BRASILEIRO DE MEDICINA VETERINÁRIA, 35, 2008, Gramado. Anais..., 2008.

OIE. Office International des Epizooties. OIE Listed Diseases, 2012. Disponível em: <http://www.oie.int/en/animal-health-in-the-world/oie-listed-diseases-2011> Acesso em: 20 jun. 2012.

OTT, S.L.; JOHNSON, R.; WELLS, S.J. Association between bovine-leukosis virus seroprevalence and herd-level productivity on US dairy farms. Preventive Veterinary Medicine, v.61, n.4, p.249-262, 2003.

RADOSTITS, O.M.; GAY, C.C.; BLOOD, D.C.; HINCHCLIFF, K.W. Clínica Veterinária: Um Tratado de Doenças dos Bovinos, Ovinos, Suínos, Caprinos e Eqüinos. 9.ed. Rio de Janeiro: Guanabara Koogan, 2002. p.940-951.

SANTOS, M.J.; TRONO, K.; LAGER, I.; WIGDOROVITZ, A. Development of a PCR to diagnose BLV genome in frozen sêmen samples. Veterinary Microbiology, v.119, p.10-18, 2007.

SILVA, R.C.; FONTANA, I.; MEIRELLES, F.C.; RUGGIERO, A.P.M.; BENATO, N.; BORGES, J.R.J. Ocorrência de leucose enzoótica bovina na forma de linfomas no Distrito Federal: relato de caso. Arquivo do Instituto Biológico de São Paulo, v.75, n.4, p.507-512, 2008. 
SPONCHIADO, D. Prevalência de anticorpos séricos anti-vírus da leucose enzoótica bovina em rebanhos da raça Holandesa Preta e Branca, criados no estado do Paraná. 2008. 101p. Dissertação (Mestrado) - Universidade Federal do Paraná, Curitiba.

RANGEL, N.M.; MACHADO, A.V. Contribuição à oncologia comparada em Minas Gerais. Arquivos da Escola Superior de Veterinária do Estado de Minas Gerais, Belo Horizonte, v.1, p.84-96, 1943. 